\title{
Chlorophyll destruction by Calanus spp. grazing on phytoplankton: kinetics, effects of ingestion rate and feeding history, and a mechanistic interpretation
}

\author{
E. J. H. Head*, L. R. Harris \\ Department of Fisheries and Oceans, Bedford Institute of Oceanography, PO Box 1006, Dartmouth, Canada B2Y 4 A2
}

\begin{abstract}
Chlorophyll destruction by Calanus spp. grazing on phytoplankton (diatoms and Phaeocystis) was assessed at stations in the Labrador Sea and off Labrador and Newfoundland (Canada). Copepods were fed at natural or diluted food concentrations over several (4 to 8) sequential $12 \mathrm{~h}$ feeding periods. Initial chlorophyll concentrations were between 0.2 and $19 \mathrm{\mu g} \mathrm{l}^{-1}$, and degrees of chlorophyll destruction were between 20 and $100 \%$. For replicate incubations, degrees of chlorophyll destruction were similar. Over all experiments degrees of destruction were generally high and variable at low ingestion rates $\left(<50 \mathrm{ng} \mathrm{chl} \mathrm{mg}^{-1} \mathrm{~h}^{-1}\right)$, decreasing to a limit of about $45 \%$ at higher ingestion rates. The relationship between ingestion rate and degree of chlorophyll destruction was not obviously affected by differences in in situ conditions (e.g. stage of the spring bloom). Filtration rates, by contrast, did vary, decreasing in the presence of an apparently noxious food (Phaeocystis) and sometimes increasing during experiments, perhaps in response to increasing hunger. Faecal pellets, collected from copepods fed at natural food concentrations, did not leak pigment over a $4 \mathrm{~d}$ period, and neither chlorophyll nor phaeopigment was lost as copepods with food in their guts were allowed to defecate for $3 \mathrm{~h}$ in filtered seawater. These results suggest that most chlorophyll destruction occurs at an early stage of feeding, and that phaeopigments are not intermediates. When we assumed in a simple model that the 'bleaching' reaction was enzymatically mediated, we found that enzyme activity varied linearly with initial ingestion rate, with a positive $y$-intercept. One interpretation of this is that there are 2 pools of enzyme activity: one associated with the copepods and the other with the phytoplankton. The algal enzymes are normally latent, but are activated by the physical break-up of cells during ingestion. At low ingestion rates the copepod enzyme can destroy all, or most, of the ingested chlorophyll, whereas at higher ingestion rates more of the destruction is due to the algal enzymes. The high variability in degrees of chlorophyll destruction reported here and elsewhere can be explained partly by differences between algal foods (e.g. differences in levels of the bleaching enzyme), partly by differences in copepod behaviour (e.g. effects on filtration rates), and partly by differences in experimental conditions, which affect the range of ingestion rates exhibited during an incubation (e.g. density of copepods, duration of incubation).
\end{abstract}

KEY WORDS: Copepod grazing Chlorophyll destruction - Kinetıcs Ingestion rate - Enzyme mediation

\section{INTRODUCTION}

Over the past decade the gut fluorescence method has frequently been used to investigate herbivorous feeding by copepods in situ (e.g. Baars \& Oosterhuis 1984, Head \& Harris 1987, Saiz \& Alcaraz 1990, Dam \& Peterson 1991, Morales et al. 1993). The method makes use of the fact that copepods convert chlorophyll a into a-type phaeopigments during digestion, so that con-

•E-mail: enca.head@maritimes.dfo.ca centrations of phaeopigments in copepods' guts are taken to be indices of levels of feeding activity. [Throughout the text the term chlorophyll $a(\mathrm{chl} a)$ is used when referring to chl a specifically, e.g. when measurements of chl a have been made by high-performance liquid chromatography (HPLC). The term chlorophyll is used more ambiguously, e.g. when some, or all, measurements have been made using Turner fluorometry. The equivalent terms are also used for phaeopigment designations.] Ingestion rates for chlorophyll have then been estimated from measurements of gut pigment levels and gut turnover 
times. The advantages of the gut fluorescence method are firstly, that a relatively large number of samples can be analysed in a relatively short period of time, and secondly, that it minimises experimental handling and thus, hopefully, its potentially stressful. effects on the animals

Criticisms of the gut fluorescence method have been made based on observations that chlorophyll ingested by copepods is not always converted into phaeopigments with $100 \%$ efficiency (e.g. Conover et al. 1986, Lopez et al. 1988, Penry \& Frost 1991, Head 1992). Instead, sometimes unidentified fluorescent products are found in copepod faeces (Head \& Harris 1992, 1994), while in other instances the portion of chl a not transformed into a-type phaeopigments is clearly not converted into any other coloured or fluorescent products (Head \& Harris 1992), and is thus said to have been 'destroyed' during feeding. In the many studies in which chlorophyll destruction has been examined, the degree to which it occurs has been found to vary between close to 0 and up to $100 \%$ (e.g. Conover et al. 1986, Lopez et al. 1988, Penry \& Frost 1991, Head \& Harris 1992, 1994)

It has been suggested that chlorophyll destruction is affected by feeding history, such that copepods which have been acclimated to high food levels in the laboratory, or which have fed at high levels of food in situ, may have a greater potential ability to destroy ingested chl a (Penry \& Frost 1991. Head 1992, Head \& Harris 1992). In addition, it has also been suggested that the extent to which destruction occurs in a given incubation varies inversely with ingestion rate (Penry \& Frost 1991) The results on which. these suggestions were based were quite variable, however, and predictions as to degrees of chlorophyll destruction likely to occur in situ were thus questionable.

In the studies mentioned above, chlorophyll destruction was examined for the entire feeding process, i.e. chlorophyll levels in the phytoplankton food were compared with phaeopigment levels in faecal pellets. This was done either by looking at pigment concentrations in the water before and after grazing by copepods (Head \& Harris 1992), or by comparing the ratios of chlorophyll and phaeopigments to a conservative tracer (e.g. biogenic silica) in phytoplankton food and faecal pellets (Penry \& Frost 1991, Head 1992). In these studies chlorophyll destruction, or disappearance, might have occurred at one of a number of stages: during ingestion (e.g because of 'sloppy' feeding); during digestion, as material passed through the gut and was acted on by digestive enzymes; or during defecation. (e.g. because of 'sloppy' defecation), or by subsequent leakage from faecal pellets, which might. or might not, have been re-ingested. Roy et al. (1989) found that pigmented particles which were $<1 \mu \mathrm{m}$, but retained by Whatman GF/F filters, were formed during 'sloppy' feeding by Calanus helgolandicus and Temora longicornis on the large diatom Coscinodiscus wailesii, but that some pigment was missing from the overall budget. In their study no faecal pellets were produced, because short incubation periods were used, and they thought that the missing pigment might have been in even smaller particles, but had no evidence to support this idea. Lopez et al. (1988) also found that chlorophyll destruction occurred prior to defecation, when Calanus pacificus with empty guts were fed with dinoflagellate cultures. Pasternak \& Drits (1988), on the other hand, reported no loss of pigment when comparing the levels of pigments in copepods' guts with those in the faecal pellets they produced during incubation in filtered seawater, and Roy \& Poulet (1990) found very low leakage rates of pigments from faecal pellets. These observations together suggest that most chlorophyll destruction occurs during ingestion, but none of the studies actually looked at destruction at each of the different stages for 1 set of animals.

In this paper we report results of experiments in which pigment destruction was examined at several stages of feeding. The experiments were carried out during May and June 1994, using copepods and natural. seawater, which were collected at 3 stations in the Canadian sub-Arctic: one on the northern Newfoundland Shelf (NNS); one in the eastern region of the central Labrador Sea (ECLS); and one, near the ice-edge, at the edge of the Labrador Shelf, off Hamilton Bank (LS). At the time of sampling the 3 stations were characterised by having: mid-spring bloom (NNS; low surface nutrients, high chlorophyll); prebloom (ECLS; high surface nutrients, low chlorophyll); and early bloom (LS; detectable surface nutrients, high chlorophyll) conditions ( $\mathrm{J}$ Cabal, L. R. Harris \& E. J. H. Head unpubl.). At each station we examined pigment budgets for groups of copepods feeding over 4 sequential $12 \mathrm{~h}$ feeding periods. In addition, we measured pigment destruction (or disappearance) during gut passage and defecation at all 3 stations, and at the mid-bloom station (NNS) we also measured leakage rates of pigments from isolated faecal pellets. For these experiments all pigment analyses were carried out using HPLC. We will show, however, that these results were similar to those obtained in feeding experiments carried out in May and June 1992 on, or just off, the southern Newfoundland Shelf, in which standard fluorometric determinations of chlorophyll and phaeopigments were made (Turner fluorometer). In these earlier experiments we examined pigment budgets over 7 or 8 sequential 12 h incubations, and also over the first $3 \mathrm{~h}$ of each (i.e. during ingestion and gut passage). 


\section{MATERIALS AND METHODS}

Collection of samples. In both 1994 and 1992 copepods were collected by vertical net tow between $100 \mathrm{~m}$ and the surface, using a ring net of $0.75 \mathrm{~m}$ diameter fitted with a $200 \mu \mathrm{m}$ mesh. The sampling stations in 1994 correspond to Stns 1,2 and 9 shown in Cabal et al. (unpubl.), and were at $50^{\circ} 52^{\prime} \mathrm{N}, 51^{\circ} 27^{\prime} \mathrm{W}$ on $27 \mathrm{May}$ (NNS); $60^{\circ} 23^{\prime} \mathrm{N}, 48^{\circ} 36^{\prime} \mathrm{W}$ (ECLS) on 30 May; and $54^{\circ} 52^{\prime} \mathrm{N}, 53^{\circ} 52^{\prime} \mathrm{W}$ (LS) on 5 June, respectively. In 1992, the copepods collected were on, or just off, the southern Newfoundland Shelf at $49^{\circ} 44^{\prime} \mathrm{N}, 49^{\circ} 38^{\prime} \mathrm{W}$ (25 May) and $51^{\circ} 19^{\prime} \mathrm{N}, 51^{\circ} 42^{\prime} \mathrm{W}$ (29 May).

At each station the copepods were rinsed, to remove adherent algae, by transferring them to a 51 plastic bucket, the bottom of which had been replaced with a $1000 \mu \mathrm{m}$ mesh, suspended in a $20 \mathrm{l}$ bucket of surface seawater. Serial transfer through several buckets of surface seawater completed the rinsing process. The copepods were then either put into two $8 \mathrm{l}$ carboys of filtered seawater (Type A Expts), or an 80 l plastic tank filled with water from the chlorophyll maximum depth (Type C Expts). The 81 carboys and 801 tank were immersed in a covered deck incubator through which surface seawater was running.

In 1994, seawater to feed to the copepods was collected at the depth of the chlorophyll maximum at each of the sampling stations $(10,10$ and $1 \mathrm{~m}$ at the NNS, ECLS and LS stations, respectively), using a biological pump fitted with a Seabird CTD probe and a submersible fluorometer. In 1992, fresh seawater 'food' was collected each day from the surface, by bucket. In both years the seawater 'food' was stored until use in plastic carboys in the deck incubator.

Type A Expts. Chlorophyll destruction by copepods in $12 \mathrm{~h}$ feeding incubations. Expts in $1994-$ Expts $A 1$ (NNS), A2 (ECLS) and A3 (LS): Copepods, which had been collected at between $08: 00$ and 10:00 $\mathrm{h}$ on each occasion, were allowed to empty their guts in filtered seawater (FSW) for $3 \mathrm{~h}$ (see above), prior to being fed. The faecal pellets produced during this part of the experiment were collected and will be referred to later as 'wild type' faecal pellets.

Prior to feeding, six 81 carboys were filled to within $600 \mathrm{ml}$ of capacity 3 with chlorophyll maximum (chl max) seawater 'food' which had been screened (100 $\mu \mathrm{m}$ mesh), mixed and sub-sampled for the determination of biogenic silica (1 $\mu \mathrm{m}$ Nuclepore filters, frozen and stored at $-20^{\circ} \mathrm{C}$ ), particulate organic carbon (POC) and particulate organic nitrogen (PON) (GF/C filters, frozen and stored at $\left.-20^{\circ} \mathrm{C}\right) ; 3$ with chl max water which had been screened (100 $\mu \mathrm{m}$ mesh), diluted 5 times with filtered seawater $(0.2 \mu \mathrm{m}$ mesh), mixed, and sub-sampled for silica, POC and PON. The first 3 carboys were the high (HI) food treatments, and the second 3, the low (LO) food treatments, in each series of incubations.

The copepods were then concentrated $(1000 \mu \mathrm{m}$ mesh), rinsed (FSW) and divided into 6 batches containing roughly equal numbers (about 350,600 and 230 per batch for Expts A1, A2 and A3, respectively). A. batch was added to each of the 6 carboys and an initial sample (1.51) was taken from each carboy after inverting it several times. This was screened through a $780 \mu \mathrm{m}$ mesh (rinsing and returning the copepods to the carboy) and sub-sampled for determinations of biogenic silica and pigments (GF/C filters, frozen and stored in liquid nitrogen for HPLC analysis). After $12 \mathrm{~h}$, the carboys were sampled (1.5 l) as they had been initially. The copepods were screened off from the ca $5 \mathrm{l}$ remaining in each carboy, rinsed and transferred to 6 fresh carboys of screened seawater, prepared as before. For this, the second feeding period, copepods which had fed previously at $\mathrm{HI}$ food were transterred to carboys containing HI food, and copepods fed previously at LO food were returned to LO food. Initial samples were taken from the carboys as for the first feeding period. Subsequently, the seawater remaining from the $3 \mathrm{HI}$ treatments of the first feeding period was combined, and the faecal pellets were collected (200 $\mu \mathrm{m}$ mesh), after removing most of the water by reverse filtration (100 $\mathrm{\mu m}$ mesh). The pellets were rinsed, re-suspended in FSW and sub-sampled for POC, PON, biogenic silica and pigments. This procedure was repeated for the pellets produced in the $3 \mathrm{LO}$ treatments.

At the end of the second $12 \mathrm{~h}$ feeding period, the experimental procedures were repeated except that this time the copepods from the HI treatments were transferred to carboys containing LO food, and the copepods from the LO treatments were transferred to carboys containing $\mathrm{HI}$ food. At the end of the third feeding period the experimental procedures were repeated, the copepods from the HI treatments being returned to $\mathrm{HI}$ food, and those from LO treatments to LO food. The experiment was ended after the fourth $12 \mathrm{~h}$ feeding period when the copepods were preserved in formalin $(2 \%)$ for subsequent enumeration, species identification and the determination of preserved dry weights. In each case copepod mortality was negligible during the course of the experiment.

Experiments in 1992 - Expts A4 (25 May) and A5 (29 May): In 1992, the experimental procedures were the same as those used in the HI treatments of the experiments carried out in 1994, except that: (1) the seawater 'food' was collected from the surface each day, so that its phytoplankton concentration and composition was variable; (2) pigment destruction was followed over 7 or 8 sequential $12 \mathrm{~h}$ feeding periods; (3) only duplicate bottles were set up for each experi- 
ment (containing between 370 and 540 copepods per 8 I incubation bottle); (4) sub-samples were taken for pigment analysis after $3 \mathrm{~h}$ of incubation, as well as at time $T=0$ and $T=12 \mathrm{~h}$; and (5) concentrations of chlorophyll and phaeopigments were measured using a Turner fluorometer.

Type B Expt. Leakage of material from faecal pellets. Expt B1 (NNS): The suspensions of each batch of faecal pellets in FSW collected in Expt A1 were divided in 2, and only half was used immediately to filter sub-samples for the determination of POC, PON, biogenic silica and pigments. The second half of each batch was left in FSW in a polycarbonate bottle in a laboratory fridge at $1^{\circ} \mathrm{C}$ (close to the in situ water tem- perature) and these were sampled after $24,48,64$ or 96 h of incubation.

Type C Expts. Pigment destruction during gut passage and defecation. Expts $C 1$ (NNS), C2 (ECLS) and $C 3$ (LS): Copepods which had been collected at the NNS, ECLS and LS stations in the morning were left in 80 l plastic tanks filled with chl max seawater (see above) until 19:00 h. Copepods were collected from the tanks by means of a 51 plastic bucket, the bottom of which had been replaced by a $1000 \mu \mathrm{m}$ mesh. A total of about 750 copepods were used in Expt C1, about 1500 in Expt C2, and about 600 in Expt C3. The copepods were rapidly divided into 15 batches of approximately equal number, which were put into $15 \times 11$ polycar-

Table 1. Average copepod densities, initial chlorophyll (chl) concentrations and average filtration rates in Type A Expts. HI: high food treatments; LO: low food treatments. "Incubations in which Phaeocystis sp. was visually abundant

\begin{tabular}{|c|c|c|c|c|c|c|}
\hline \multicolumn{2}{|c|}{$\begin{array}{l}\text { Expt } \\
\text { (Feeding period) }\end{array}$} & \multirow{5}{*}{$\begin{array}{c}\text { Copepod } \\
\text { density (ind. } \mathrm{I}^{-1} \text { ) } \\
42.8\end{array}$} & \multirow{5}{*}{$\begin{array}{c}\text { Copepod } \\
\text { dry weight }\left(\mathrm{mg} \mathrm{l}^{-1}\right) \\
23.5\end{array}$} & \multirow{2}{*}{$\begin{array}{c}\text { Initial chl concen- } \\
\text { tration }\left(\mu \mathrm{g} \mathrm{l}^{-1}\right) \\
7.41\end{array}$} & \multirow[t]{2}{*}{$\begin{array}{l}\text { Filtration rate }(3 \mathrm{~h}) \\
\qquad\left(\mathrm{ml} \mathrm{m \textrm {m } ^ { - 1 }} \mathrm{h}^{-1}\right)\end{array}$} & \multirow{2}{*}{$\begin{array}{c}\begin{array}{c}\text { Filtration rate }(12 \mathrm{~h}) \\
\left(\mathrm{ml} \mathrm{mg}^{-1} \mathrm{~h}^{-1}\right)\end{array} \\
5.22\end{array}$} \\
\hline A 1 & $\mathrm{HI}(1)$ & & & & & \\
\hline & $\mathrm{HI}(2)$ & & & 8.85 & & 6.29 \\
\hline & LO (3) & & & 1.33 & & 3.74 \\
\hline & LO (4) & & & 1.46 & & 7.13 \\
\hline \multirow[t]{4}{*}{ A 1} & LO (1) & 45.0 & 25.3 & 1.64 & & 6.13 \\
\hline & LO (2) & & & 1.89 & & 6.51 \\
\hline & $\mathrm{HI}(3)$ & & & 7.64 & & 7.90 \\
\hline & $\mathrm{HI}$ (4) & & & 7.44 & & 7.23 \\
\hline \multirow[t]{4}{*}{$\mathrm{A} 2$} & $\mathrm{HI}(1)$ & 71.5 & 206 & 1.31 & & 3.40 \\
\hline & $\mathrm{HI} \quad(2)$ & & & 1.25 & & 2.19 \\
\hline & LO (3) & & & 0.33 & & 2.07 \\
\hline & LO (4) & & & 0.31 & & 1.60 \\
\hline \multirow[t]{4}{*}{$\mathrm{A} 2$} & LO (1) & 81.3 & 23.1 & 0.20 & & 1.37 \\
\hline & LO (2) & & & 0.21 & & 0.68 \\
\hline & HI (3) & & & 1.84 & & 2.20 \\
\hline & $\mathrm{HI}$ (4) & & & 1.30 & & 2.02 \\
\hline \multirow[t]{4}{*}{ A3 } & $\mathrm{HI}(1)$ & 28.3 & 27.0 & 7.98 & & 1.52 \\
\hline & $\mathrm{HI}(2)$ & & & 9.56 & & 2.57 \\
\hline & LO (3) & & & 1.90 & & 5.63 \\
\hline & LO (4) & & & 1.89 & & 5.46 \\
\hline \multirow[t]{4}{*}{$\mathrm{A} 3$} & LO (1) & 29.5 & 28.3 & 1.47 & & 3.81 \\
\hline & LO (2) & & & 1.68 & & 4.08 \\
\hline & $\mathrm{HI}(3)$ & & & 10.84 & & 4.24 \\
\hline & $\mathrm{HI}$ (4) & & & 7.30 & & 5.23 \\
\hline \multirow[t]{7}{*}{ A4 } & (1) & .72 .2 & 14.8 & 15.74 & 9.81 & 9.35 \\
\hline & (2) & & & 18.63 & 10.77 & 9.27 \\
\hline & (3) & & & 7.70 & 9.39 & 10.26 \\
\hline & (4) & & & 3.59 & 12.08 & 11.16 \\
\hline & (5) & & & 3.17 & 10.42 & 9.73 \\
\hline & (6) & & & 7.67 & 13.12 & 11.53 \\
\hline & (7) & & & 9.44 & 10.29 & 8.74 \\
\hline \multirow[t]{8}{*}{ A5 } & (1) & 59.8 & 24.6 & 7.63 & 458 & 5.70 \\
\hline & (2) & & & 6.72 & 15.40 & 8.48 \\
\hline & (3) & & & 4.97 & - & $3.06^{\circ}$ \\
\hline & (4) & & & 5.07 & $2.83^{\circ}$ & $2.72^{\circ}$ \\
\hline & (5) & & & 5.37 & 9.77 & 9.62 \\
\hline & (6) & & & 4.64 & 13.91 & 8.89 \\
\hline & (7) & & & 1.74 & 10.76 & 7.09 \\
\hline & (8) & & & 1.58 & 11.13 & 6.96 \\
\hline
\end{tabular}


bonate bottles filled with filtered seawater. Immediately, the contents of 3 bottles were filtered $(T=0)$ on to GF/C filters ( $47 \mathrm{~mm}$ ). The number of copepods on each filter was counted, and the filters were put into cryovials, frozen and stored in liquid nitrogen for HPLC analysis. The remaining bottles were put in the deck incubator and 3 bottles were sampled (as at $T=0$ ) at $30,60,120$ and $180 \mathrm{~min}$.

Analysis of samples. HPLC identifications and quantifications of pigments, using known standards, were as described in Head \& Harris (1992). Concentrations of biogenic silica, and of chlorophyll and phaeopigments using a Turner fluorometer, were measured as in Head (1992). POC and PON concentrations were determined using a Perkin Elmer $2400 \mathrm{CHN}$ Analyser.

\section{RESULTS}

\section{Type A Expts. Destruction of chlorophyll during $12 \mathrm{~h}$ feeding incubations}

Feeding experiments in 1994: Expts A1, A2 and A3

Copepod densities in the carboys varied in terms of numbers by a factor of $>2$ between experiments, but in terms of preserved dry weight, the range was only between 20 and $30 \mathrm{mg} \mathrm{l}^{-1}$ (Table 1). Calanus finmarchicus was always the most abundant species. $C$. glacialis was the second most abundant on the NNS and $C$. hyperboreus was the second most abundant at the other 2 stations (Table 2 ).

The pigment compostion of the algal food was very similar in all 3 experiments (Table 3). Chl a (+ allomer) and fucoxanthin were the most abundant pigments: both are characteristic of diatoms. At the NNS and LS stations, diatoms were visually extremely abundant in the water, but at the ECLS station no large phytoplankton were seen. At the ECLS station, the presence of chl $c 3$, and the relatively high ratio of pigment (chl $a+a-$ type phaeopigment):biogenic silica suggest that the prymnesiophyte Phaeocystis sp. might have been present, as it had been further south in water in 1992 (see Expt A5).

Two methods were used to calculate the degree of chl a destruction. In the first, we compared the amount of chl a (+ allomer + chlorophyllide a) consumed with the amount of a-type phaeopigment (pyrophaeophorbide $a+$ pyrophaeophytin a + phaeophytin a) produced, by measuring their concentrations in the seawater before and after grazing (Fig. 1). In the second, we compared the ratios of total a-type chlorin (chls + fildeusj io biogenic siiica in particulate maternal betore grazing with those in faecal pellets collected after grazing (Table 4). For the latter calculation it was
Table 2. Calanus spp. Percentage species and stage compositions of copepods in Type A Expts

\begin{tabular}{|c|c|c|c|}
\hline Expt & $\begin{array}{c}\mathrm{C} \\
\text { hyperboreus }\end{array}$ & $\begin{array}{c}\text { C. } \\
\text { glacialis }\end{array}$ & $\begin{array}{c}C . \\
\text { finmarchicus }\end{array}$ \\
\hline \multicolumn{4}{|l|}{$\mathrm{A} 1$} \\
\hline$\%$ all copepods & 8 & 33 & 59 \\
\hline \multicolumn{4}{|c|}{$\%$ species at stage } \\
\hline VIF & 2 & 35 & 96 \\
\hline $\mathrm{v}$ & 79 & 63 & 3 \\
\hline IV & 5 & 2 & 0 \\
\hline III & 15 & 0 & 0 \\
\hline \multicolumn{4}{|l|}{$\mathrm{A} 2$} \\
\hline$\%$ all copepods & 46 & 5 & 49 \\
\hline \multicolumn{4}{|c|}{$\%$ species at stage } \\
\hline VIF & 0 & 0 & 73 \\
\hline V & 1 & 54 & 23 \\
\hline IV & 35 & 46 & 4 \\
\hline IIl & 64 & 0 & 0 \\
\hline \multicolumn{4}{|l|}{ A3 3} \\
\hline$\%$ all copepods & 31 & 12 & 55 \\
\hline \multicolumn{4}{|c|}{$\%$ species at stage } \\
\hline VIF & 32 & 2 & 81 \\
\hline V & 60 & 61 & 16 \\
\hline IV & 6 & 10 & 1 \\
\hline III & 2 & 0 & 0 \\
\hline \multicolumn{4}{|l|}{$\mathrm{A} 4$} \\
\hline$\%$ all copepods & 12 & 3 & 85 \\
\hline \multicolumn{4}{|c|}{$\%$ species at stage } \\
\hline VIF & 0 & 1 & 84 \\
\hline V & 68 & 99 & 11 \\
\hline IV & 10 & 0 & 5 \\
\hline III & 23 & 0 & 0 \\
\hline \multicolumn{4}{|l|}{ A5 } \\
\hline$\%$ all copepods & 16 & 48 & 36 \\
\hline \multicolumn{4}{|c|}{$\%$ species at stage } \\
\hline VIF & 0 & 15 & 95 \\
\hline V & 22 & 58 & 5 \\
\hline IV & 5 & 5 & 0 \\
\hline III & 65 & 14 & 0 \\
\hline 11 & 8 & 8 & 0 \\
\hline
\end{tabular}

Table 3. Pigment composition and concentration, and pigment silica ratios of food used in the first $\mathrm{HI}$ food treatment in Expts A1, A2 and A3. Pigments accounting for $<2 \%$ of the total are not included in the compositional analysis

\begin{tabular}{|c|c|c|c|}
\hline \multirow{2}{*}{$\begin{array}{l}\text { Pigments (in order of } \\
\text { retention times) }(\%)\end{array}$} & \multicolumn{3}{|c|}{ Expt } \\
\hline & $\mathrm{A} 1$ & $\mathrm{~A} 2$ & A3 \\
\hline $\mathrm{Chl} \mathrm{c3}$ & 0 & 2 & 0 \\
\hline Chlorophyllide a & 3 & 0 & 5 \\
\hline Chl $c 1+c 2$ & 8 & 8 & 9 \\
\hline Fucoxanthin & 27 & 23 & 27 \\
\hline 19-Hexanoyloxyfucoxanthin & 2 & 0 & 0 \\
\hline Pyrophaeophorbide a & 2 & 10 & 6 \\
\hline Diadinoxanthin & 5 & 3 & 4 \\
\hline Chl a (+ allomer $)$ & 49 & 49 & 42 \\
\hline $\begin{array}{l}\text { Initial a-type chl + a-type } \\
\text { phaeonigment ronr }\left(\ln \mathrm{I}^{-1}\right)\end{array}$ & 7.78 & 1.62 & 10.05 \\
\hline $\begin{array}{l}\text { Initial (a-type chl + phaeopig- } \\
\text { ment) : silica ratio ( } \mu \mathrm{g}: \mu g \text {-at.) }\end{array}$ & 1.35 & 1.86 & 1.06 \\
\hline
\end{tabular}




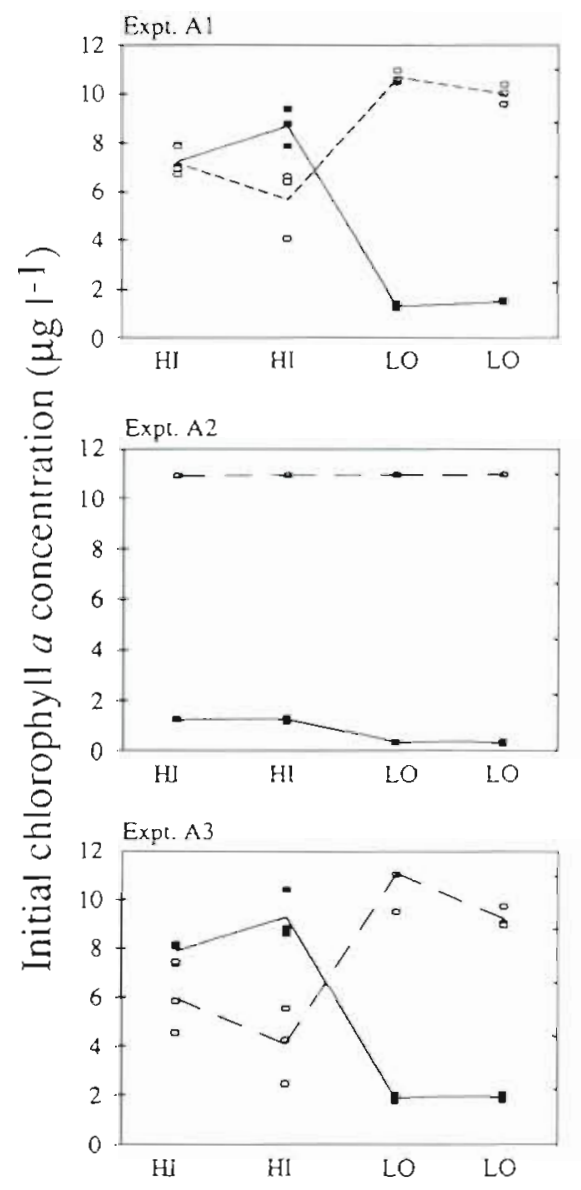

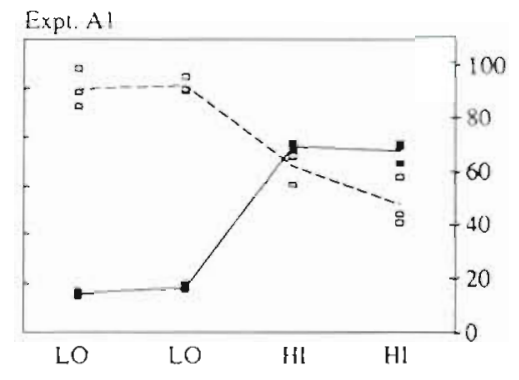
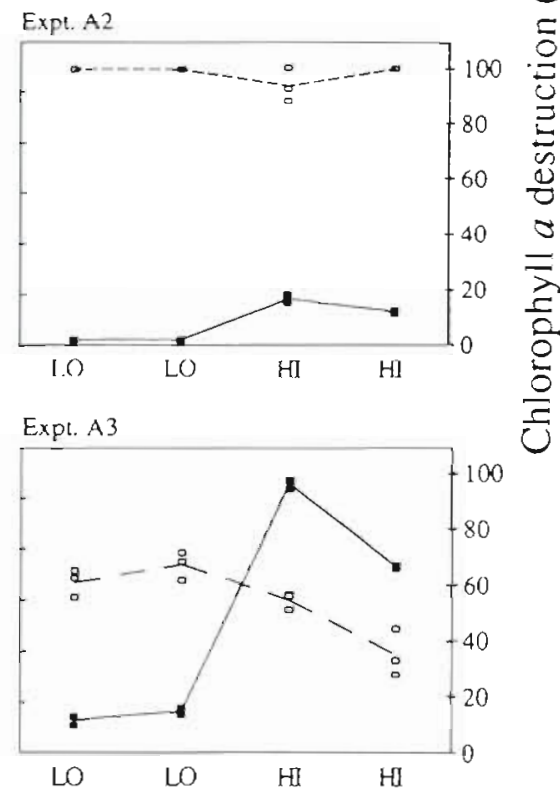

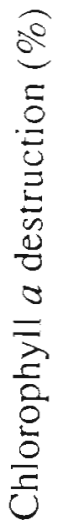

Fig. 1. Initial chlorophyll a (chl a) concentrations $(-)$ and degrees of chl a destruction (a) durning sequential $12 \mathrm{~h}$ feeding periods in Expts A1, A2, and A3. HI: high food treatments; LO: low food treatments important that biogenic silica concentrations remained constant throughout the incubations, i.e. that the biogenic silica was conserved during feeding. We found that this was the case. In Expt A2, feeding rates were so low in both $\mathrm{HI}$ and LO treaments that silica concentrations could not be measured accurately in the faecal pellets. Thus, the silica ratio method was only used for Expts $A 1$ and $A 3$.

For both methods, it was assumed that the 3 a-type phaeopigments were the only important end-products of chl a degradation. This assumption was confirmed by assessing the pigment composition of faecal peliets (Fig. 2). There was only 1 unidentified peak (retention time ca $12.5 \mathrm{~min}$ ) that ever made a significant contribution to the total fluorescent pigment pool. Although it might have been derived from chl $a_{1}$ it was probably not a simple a-type phaeopigment because it did not have the characteristic ratio between its fluorescence and absorption peak areas. It was, in any case, only important in pellets produced in incubations at the NNS station, and then only when the copepods were fed at LO food concentrations. The chromatograms (Fig. 2) do not show the region where the cholesterol esters of the phaeophorbides would have eluted
(>25 min), but in runs which were extended for up to 35 min there were no more fluorescent peaks. 'Wild type' faecal pellets contained the same pigments as did those produced during the experiments, but with higher proportions of the intact algal chlorophylls, perhaps because of contamination with adherent algae.

For Expts A1 and A3, both methods of assessing pigment destruction gave similar results (Fig. 1, Table 4). Both showed that degrees of chl a destruction were higher in the LO than in the HI treatments, and that degrees of destruction were generally higher in Expt A1 than in equivalent incubations in Expt A3, even though initial chlorophyll concentrations were similar. For Expt A.2, in which only budget calculations were possible, the degree of chl a destruction. was always close to $100 \%$. In fact, in this case, there was some atype phaeopigment present in the water before grazing which usually decreased in concentration during incubation, so that calculated degrees of chl a destruction were apparently $>100 \%$. In Fig 1 and in our later discussion, however, $100 \%$ was used as maximum.

By comparing the POC:biogenic silica and PON:biogenic silica ratios in food and faecal pellets in Expts A 1 . and $A 3$, assimilation efficiencies for the carbon and 
Table 4. Estimates of pigment destruction and assimilation efficlencies for carbon and nitrogen in Expts A.1 and A3, using the sllica ratio method. 'Pigment'. sum of chl a (+ allomer + chlorophyllide a) plus a-type phaeopigment (pyrophacophorbide a + pyrophaeophytin a + phaeophytin a). POC: particulate organic carbon; PON: particulate organic nitrogen

\begin{tabular}{|c|c|c|c|c|c|c|c|c|c|c|}
\hline \multicolumn{2}{|c|}{$\begin{array}{l}\text { Expt } \\
\text { (Feeding } \\
\text { period) }\end{array}$} & \multirow{2}{*}{ 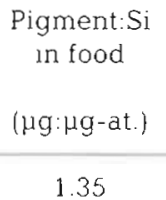 } & \multirow{2}{*}{ 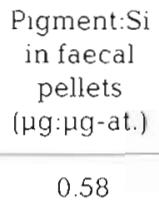 } & \multirow{2}{*}{$\begin{array}{c}\text { Pigment } \\
\text { destruction } \\
(\%) \\
57\end{array}$} & \multirow{2}{*}{$\begin{array}{c}\text { POC:Si } \\
\text { in food } \\
\text { ( } \mu \mathrm{g}: \mu \mathrm{g} \text {-at.) } \\
104.8\end{array}$} & \multirow{2}{*}{ 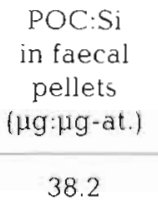 } & \multirow{2}{*}{$\begin{array}{c}\text { POC } \\
\text { assimilation } \\
(\%) \\
64\end{array}$} & \multirow{2}{*}{$\begin{array}{c}\text { PON:Si } \\
\text { in food } \\
\begin{array}{c}(\mu g: \mu g-a t .) \\
16.0\end{array}\end{array}$} & \multirow{2}{*}{ 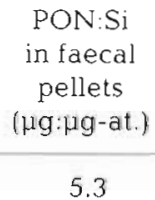 } & \multirow{2}{*}{$\begin{array}{c}\text { PON } \\
\text { assimilation } \\
\frac{(\%)}{67}\end{array}$} \\
\hline & HI $(1)$ & & & & & & & & & \\
\hline & HII (2) & 1.33 & 0.78 & 49 & 104.8 & 26.7 & 74 & 16.1 & 4.3 & 73 \\
\hline & LO (3) & 1.06 & 0.18 & 83 & 102.8 & 65.5 & 36 & 18.2 & 9.9 & 45 \\
\hline & LO (4) & 1.39 & 0.30 & 79 & 75.7 & 31.2 & 59 & 15.4 & 7.7 & 50 \\
\hline A 1 & LO (1) & 0.94 & 0.11 & 89 & 136.6 & 51.9 & 62 & 18.4 & 9.3 & 49 \\
\hline & LO (2) & 1.33 & 0.20 & 85 & 136.6 & 65.6 & 52 & 20.7 & 13.1 & 37 \\
\hline & HI (3) & 1.40 & 0.44 & 69 & 99.6 & 18.7 & 81 & 15.4 & 2.8 & 82 \\
\hline & $\mathrm{HI}$ (4) & 1.41 & 0.62 & 56 & 86.4 & 18.3 & 79 & 14.6 & 3.2 & 78 \\
\hline A 3 & HI (1) & 1.06 & 0.74 & 30 & 82.0 & 23.2 & 72 & 10.2 & 3.7 & 64 \\
\hline & $\mathrm{HI}(2)$ & 1.11 & 0.92 & 17 & 79.5 & 14.1 & 82 & 9.9 & 1.9 & 81 \\
\hline & LO (3) & 1.17 & 0.37 & 68 & 49.9 & 30.8 & 38 & 9.9 & 4.7 & 52 \\
\hline & LO (4) & 1.11 & 0.40 & 64 & 66.9 & 52.9 & 21 & 10.2 & 5.7 & 44 \\
\hline A 3 & LO (1) & 0.86 & 0.32 & 63 & 86.8 & 12.3 & 86 & 10.6 & 2.1 & 80 \\
\hline & LO (2) & 0.91 & 0.50 & 45 & 71.9 & 16.3 & 77 & 10.0 & 3.0 & 70 \\
\hline & HI (3) & 1.34 & 1.06 & 21 & 70.5 & 13.3 & 81 & 11.2 & 2.0 & 82 \\
\hline & $\mathrm{HI}$ (4) & 1.23 & 0.85 & 31 & 68.2 & 18.4 & 73 & 12.3 & 2.3 & 81 \\
\hline
\end{tabular}
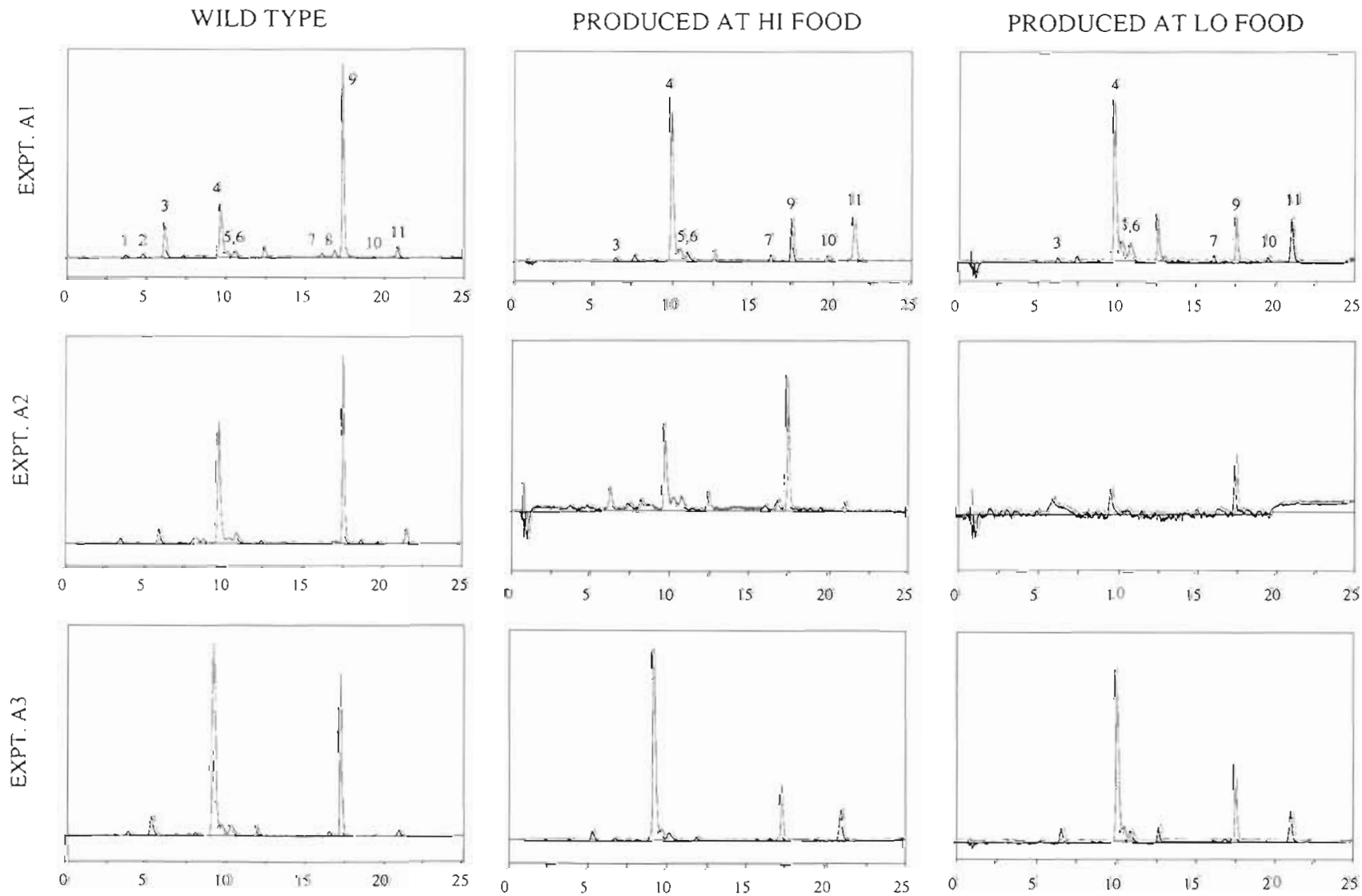

Fig. 2. Fluorescence chromatograms of samples of faecal pellets collected from copepods which had fed in situ (column 1) or in feeding incubations (columns 2 and 3). Identified peaks: (1) chl $c 3 ;(2)$ chlorophyllide $a_{;}(3) \mathrm{chl} c(c 1+c 2)$; (4) pyrophaeophorbide $a_{i}$ (5) phaeoporphyrun $c$-like; (6) phaeoporphyrin $c$-like; (7) chl $b$; (8) chl a allomer; (9) chl $a_{;}$(10) phaeophytin a; (11) pyrophaeo- 
nitrogen could be determined (Table 4). These tended to be higher in HI treatments than in LO treatments.

\section{Feeding experiments in 1992: Expts A4 and A5}

The water fed to the copepods during the first two $12 \mathrm{~h}$ feeding periods was collected at the same time as the copepods had been, so that the first 2 feeding periods of Expts A4 and A5 were analogous to the first 2 of the HI/LO treatments in the 1994 experiments. The densities of copepods, in terms of both numbers and dry weight, were similar to those used in 1994 (Table 1), and the same 3 Calanus spp. accounted for $100 \%$ of the copepods (Table 2).

The pigment composition of some of the seawater 'food' samples was assessed using HPLC, and its composition was consistent with visual observations that diatoms were dominant, except for the seawater 'food' used during the third and fourth feeding periods of Expt A5. The seawater used in these feeding periods was collected at the same time and large colonies of Phaeocystis sp. were clearly visible. HPLC analysis showed low levels (ca $2 \%$ ) of chl $c 3$ and 19-hexanoyloxyfucoxanthin, both of which are characteristic of Phaeocystis sp. (Jeffrey \& Wright 1994).

The pigment composition of faecal pellets collected following each incubation period was assessed by HPLC analysis. The pellets contained the same fluorescent pigments as did those from the 1994 experiments. The unidentified peak at ca 12.5 min was sometimes seen, and was most prevalent in pellets produced during the fourth and fifth feeding periods of Expt A4, i.e. when copepods which had been feeding at high food concentrations were transferred to lower food concentrations (Fig. 3)

In Expts A4 and A5 degrees of chlorophyll destruction were calculated from the concentrations of chlorophyll and phaeopigments, determined by Turner fluorometry, in the water before and after grazing (Fig. 3). Initial samples often had apparently negative concentrations of phaeopigment, because of interference by chl c. In these cases initial phaeopigment concentrations were set to zero in the calculations. The results were similar to those obtained in the 1994 experiments, although the results from the third and fourth feeding periods of Expt A5 were somewhat anomalous. Filtration rates in these incubations were also anomalously low (Table 1), and this may have been because Phaeocystis sp. was present. For these feeding periods, the levels of pigment destruction in the 2 incubation bottles were rather different, in contrast to the results for all other feeding periods (Fig. 3). Here, however, the bottles were not true replicates. For 1 carboy the Phaeocystis sp. food had been

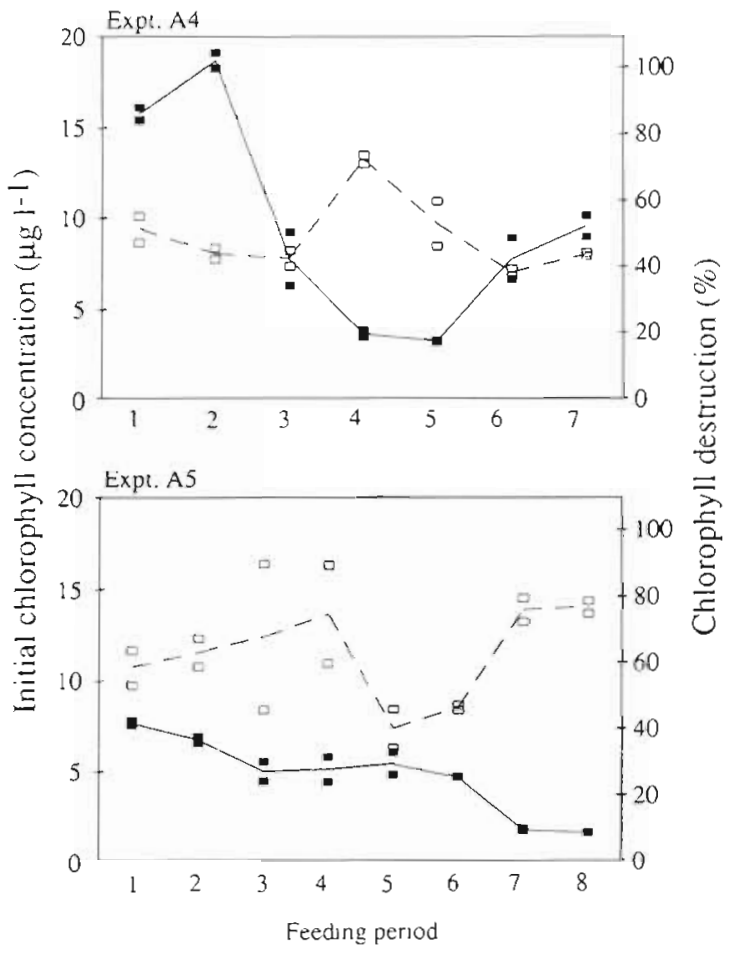

Fig. 3. Initial chlorophyll concentrations (-) and degrees of chlorophyll destruction ( $($ ) during sequential feeding periods in Expts $\mathrm{A} 4$ and $\mathrm{A} 5$

screened at $100 \mu \mathrm{m}$ mesh, as in all other incubations, but for the second, it was not screened. HPLC analysis of screened and unscreened water showed that screening did not change the concentration of any of the pigments very much, but it probably broke up the large Phaeocystis sp. colonies. Also, although we averaged the filtration rates between the 2 carboys in Table 1, rates in the screened carboys were actually

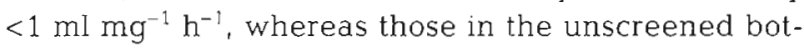
tles were between 2 and $4 \mathrm{ml} \mathrm{mg}^{-1} \mathrm{~h}^{-1}$. The highest degrees of chlorophyll destruction (Fig. 3) occurred in each of the screened bottles, in which filtration and ingestion rates were much lower than those in the unscreened carboys.

In 25 out of 28 incubations degrees of pigment destruction over the first $3 \mathrm{~h}$ of incubation (data not shown) were apparently equal to, or higher than, degrees of destruction over the whole $12 \mathrm{~h}$ feeding period. Degrees of destruction might have been overestimated during the first $3 \mathrm{~h}$, however, because changes in phaeopigment concentrations were probably not determined very accurately during this period. This is because initial samples often appeared to have negative phaeopigment concentrations, because of interference by chl $c$, which were set to zero in calculations. After $3 \mathrm{~h}$, phaeopigment concentrations were apparently only slightly above zero, but these values 
were probably artificially low, again because of interference by chl $c$. After 12 h of grazing the effect of chl $c$ became less important, however, because its concentration was much lower.

Feeding rates and chlorophyll destruction in 1994 and 1992

In the 1992 experiments, filtration rates (12 or $3 \mathrm{~h}$ ) were relatively high and relatively constant throughout the experiments, except when Phaeocystis sp. was present (Table 1). Thus, chlorophyll ingestion rates increased linearly with increasing initial food concentration, except when Phaeocystis sp. was present (Fig. 4). In 1994, by contrast, filtration rates were variable: they were lowest at the ECLS (pre-bloom) station, and highest at the NNS (mid-bloom) station. At the LS (early bloom) station, they increased markedly during the experiments, and there was a similar trend at the NNS station. Because of this variability, the relationship between ingestion rate and initial food concentration was not as obviously linear.

In 1992 and 1994, the degree of chlorophyll destruction showed considerable variability with ingestion rate, but overall it was generally between 60 and $100 \%$ at initial ingestion rates of $<20 \mathrm{ng} \mathrm{mg}^{-1} \mathrm{~h}^{-1}$, somewhere between about 30 and $70 \%$ at initial ingestion rates of between 25 and $60 \mathrm{ng} \mathrm{mg}^{-1} \mathrm{~h}^{-1}$, and between 40 and $50 \%$ at initial ingestion rates of $>75 \mathrm{ng} \mathrm{mg}^{-1} \mathrm{~h}^{-1}$ (Fig. 4).

\section{Type B Expts. Leakage of pigment, POC, PON and biogenic silica from faecal pellets produced by copepods in Expt A1}

Isolated faecal pellets produced in the HI treatments of Expt A1 did not leak pigment, biogenic silica, POC or PON over periods of up to $4 \mathrm{~d}$ (Fig. 5). In the LO treatments, however, biogenic silica and POC levels remained the same for pellets incubated for 1,2 or $3 d$, while pigment and PON levels were apparently 20 to $30 \%$ lower after $2 \mathrm{~d}$. The sample of faecal pellets which had been incubated for $4 \mathrm{~d}$ showed lower levels for every component. This might have been because the initial suspension of faecal pellets was not split exactly evenly.

\section{Type C Expts. Destruction of phaeopigment during gut passage and defecation}

Copepod concentrations varied between 44 and 70 ind. $\mathrm{l}^{-1}$ in incubation bottles in Expt C1, between
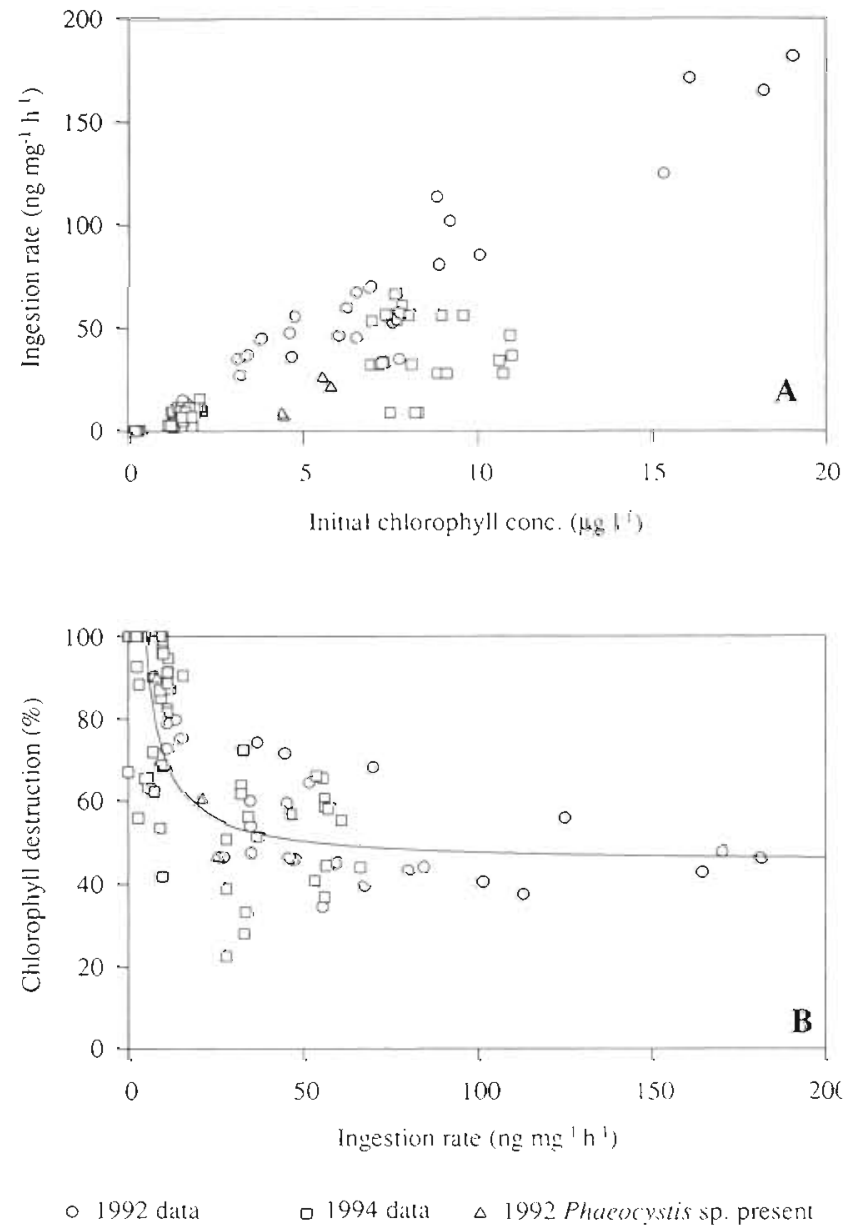

Fig. 4. Relationships between (A) initial ingestion rate and initial chl a (1994 data; Expts A1 to A.3) or initial chlorophyll (1992 data; Expts A4 and A5) concentration and between (B) ingestion rate and the observed degree of chl a (1994 data) or chlorophyll destruction (1992 data). The line in the lower panel was derived from the linear regression shown in Fig. 7

83 and 170 ind. $\mathrm{l}^{-1}$ in Expt C2 and between 29 and 60 ind. $\mathrm{I}^{-1}$ in Expt C3. In these experiments, phaeopigment would have been in the copepods' guts at the begining of each incubation, and in faecal pellets in suspension at the end. We did not attempt to separate the 2 pools: we were only concerned with examining the overall pigment budget. Chl a was also present in the samples. It might have been in copepods' guts at the start of each experiment, but it might also have been in algae which we had not managed to rinse off the copepods. Chl a was included in the pigment budgets, although concentrations did not change systematically during incubation. The concentrations of $a$ tyne chls + phaeos per copepod varicd considerably between experiments (Fig. 6), with chlorophyll accounting for between 16 and $56 \%$ of the total in Expt C1, between 9 and $100 \%$ in Expt C2 and between 2 

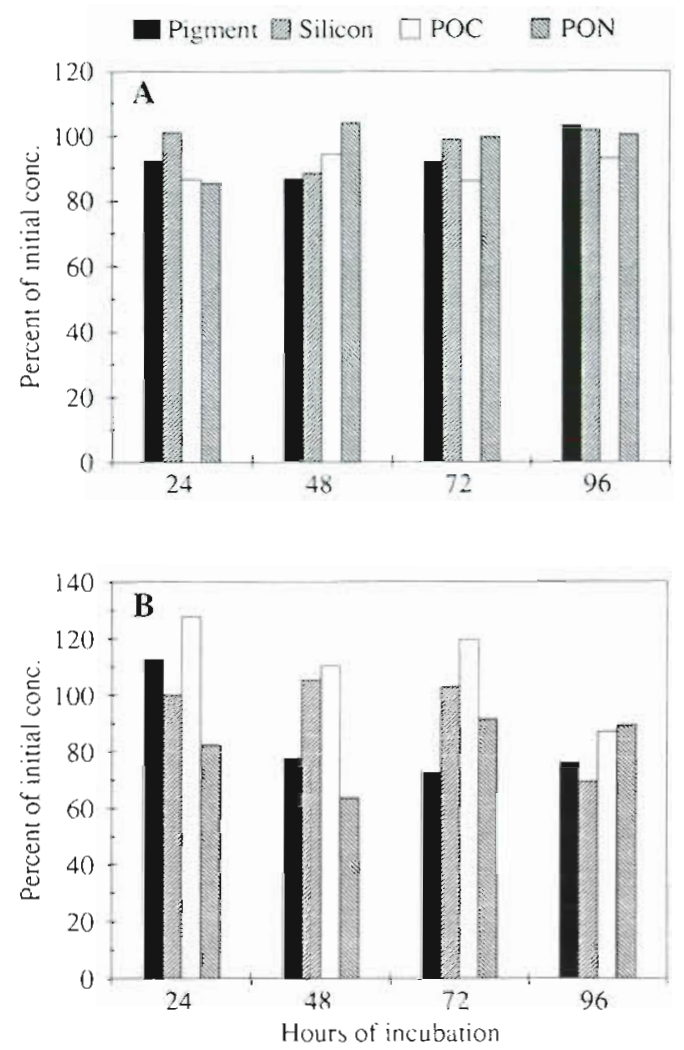

Fig. 5. Leakage of material from faecal pellets collected during Expt A.1. Samples of faecal pellets from (A) HI and (B) LO treaments were split in half and one half was sub-sampled immediately, while the other was incubated in filtered seawater. Concentrations of pigments (a-type chls + phaeos), silica, particulate organic carbon (POC) and particulate organic nitrogen (PON) in the suspensions after incubation are expressed as a percentage of the concentrations in the suspensions sampled immediately after collection

and $4 \%$ in Expt C3. The sum of the concentrations of a-type chls and phaeos would not have exceeded 0.5 . 0.05 and $2 \mu \mathrm{g} \mathrm{l}^{-1}$ in. Expts C1, C2 and C3, respectively, even if all pigment had been in algae and faeces in the water. There was some variability in the concentrations of pigment per copepod, but progressive pigment destruction, or loss, did not occur during any of the experiments.

\section{DISCUSSION}

Degrees of chl a destruction in replicate carboys in Type A Expts were very consistent (Figs. 1 \& 3 ). This is an important point, because degrees of pigment destruction reported in other studies have often been very variable (e.g. Conover et al. 1986, Lopez et al 1988, Penry \& Frost 1991, Head \& Harris 1992) and results have thus been subject to questions concerning

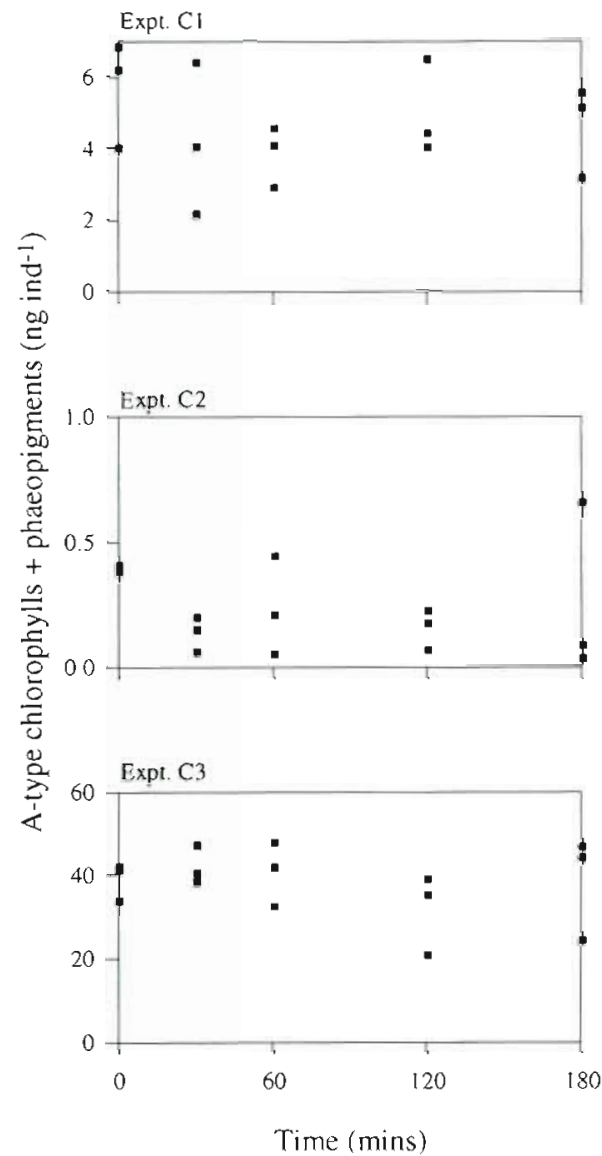

Fig. 6. Pigment kinetics during gut passage and defecation Pigment concentrations (a-type chls + phaeos) were measured for each bottle by filtering the entire contents, without separating copepods from their faeces. Concentrations are expressed per copepod, because the pigment content of each bottle was derived from pigment initially in copepods' guts, and there were different numbers of copepods in each bottle

experimental and analytical techniques. Despite the low variability between replicates, however, there was a wide range of degrees of chlorophyll destruction (25 to $100 \%$. The most important factor affecting the degree to which it occurred was ingestion rate. This was also surmised by Penry \& Frost (1991), but here we have shown how variations in filtration rate may confound the expected effect of food concentration on ingestion rate (and hence on the degree of chlorophyll destruction). Thus, for a given population of copepods feeding at a given filtration rate, a decrease in food concentration will lead to a decrease in ingestion rate and to an increase in the degree of chlorophyll destruction, but if a change of food type induces a change in filtration rate (e.g. the introduction of Phaeocystis sp. in Expt A5), then even if the food concentration remains constant, ingestion rate and degree of chlorophyll destruction will. change. Changes in filtra- 
tion rates can be caused by factors other than the introduction of a different type of food. For example, in Expts $\mathrm{A} 1$ and $\mathrm{A} 3$, filtration rates increased during the $2 \mathrm{~d}$ of the experiment. This might have been because the copepods were initially suffering from capture stress and were gradually becoming more active; or because they were becoming increasingly hungry, because they were depleting the food significantly during each $12 \mathrm{~h}$ feeding period (e.g. Hassett \& Landry 1988); or because we were sampling during the early or mid-spring bloom period, i.e. at a time when their filtration rates were increasing naturally to some physiological maximum (e.g. Runge 1980). In Expt A4, where copepod filtration rates were highest, they were relatively constant throughout the experiment. Perhaps these filtration rates were maximal values, which could not have been increased in response to hunger. In contrast, copepods from the ECLS station (Expt A.2, pre-bloom) might have had low filtration rates because they had not yet started feeding actively. Another reason, however, might have been the presence of Phaeocystis sp., and the fact that the seawater was screened before being fed to copepods (cf. Expt A5)

The combined results of the Type B and Type C Expts suggest that most chl a destruction by copepods does not occur during gut passage, nor because of loss during 'sloppy' defecation, nor because of leakage of pigment from faecal pellets, either in the presence or absence of copepods. Instead, it occurs at an earlier stage. Some leakage might occur during 'sloppy' feeding (Roy et al. 1989), but it seems unlikely that close to $100 \%$ of ingested chlorophyll could ever be lost in this way. Another explanation might be that copepods contain an enzyme (or a number of enzymes) which catalyse the formation of colourless residues. Indeed the presence of such an enzyme was postulated, over 20 years ago, as a mechanism by which Daphnia destroyed chlorophyll when grazing on algal cultures (Daley 1973). If such an enzyme, or enzyme system, does exist, then its action occurs early during ingestion and is relatively rapid. We make these assertions because levels of intact chlorophyll are usually very low in copepods' guts, and because in experiments in which prestarved Calanus spp. were fed with diatoms, only pyrophaeophytin $a$ and pyrophaeophorbide $a$ and no other fluorescent intermediates were found during the early stages ( 0 to $30 \mathrm{~min}$ ) of gut filling (Head unpubl. data). It is unlikely the phaeopigments themselves are intermediates, since they are not degraded during gut passage. Thus, when chl $a$ is ingested its degradation goes via one of 2 pathways: one leads to phaeopigment formation and the other to colourless residues. This conclusion is consistent with ideas concerning chl a degradation in both higher plants (Brown et al. 1991) and senescent algae (Spooner et al. 1994), and with observations of chl a destruction in cell free extracts of diatoms (Owens \& Falkowski 1982). The reactions by which chl $a$ is rendered colourless are largely unknown, although oxidation and ring cleavage are probably involved. In our discussion, for convenience, we will call the responsible enzyme (or enzymes) simply the 'chlorophyll bleaching enzyme' (CBE). According to this view, the degree of chl a destruction should be regulated by the level of $\mathrm{CBE}$. In order to examine the way in which CBE activity might vary with ingestion rate we used the following expression:

\section{$\%$ pigment destruction $=\mathrm{CBE} \times 100 /$ ingestion rate}

CBE activities were calculated from initial ingestion rates and measured degrees of chlorophyll destruction. This model is simplistic, because the values that were used for ingestion rates were the initial instantaneous values, and the degrees of destruction were the $12 \mathrm{~h}$ integrated values, but, nevertheless, the relationship between estimates of $\mathrm{CBE}$ activity and intial ingestion rate was strikingly linear $\left(r^{2}=0.94, N=102\right)$, and the linear regression gave a positive $y$-intercept (Fig. 7). The simplest explanation for such a relationship is as follows. There is a basal level of CBE activity (or low, constant rate of CBE synthesis) in copepods, which is represented by the intercept on the $y$-axis. There is also a second component of the total CBE activity whose concentration (i.e. activity) is directly proportional to the uptake of chlorophyll. There are 2 possible sources for this second component. The first is copepods themselves, if increased ingestion stimulates CBE synthesis. This is probably not the primary source, however, because if it were, then it is likely that at high ingestion rates the rate of $C B E$ synthesis itself would have become rate-limiting, and the relationship would have flattened off. The second possibility is that the variable component derives from the algae. This seems to be a more plausible option. Owens \& Falkowski

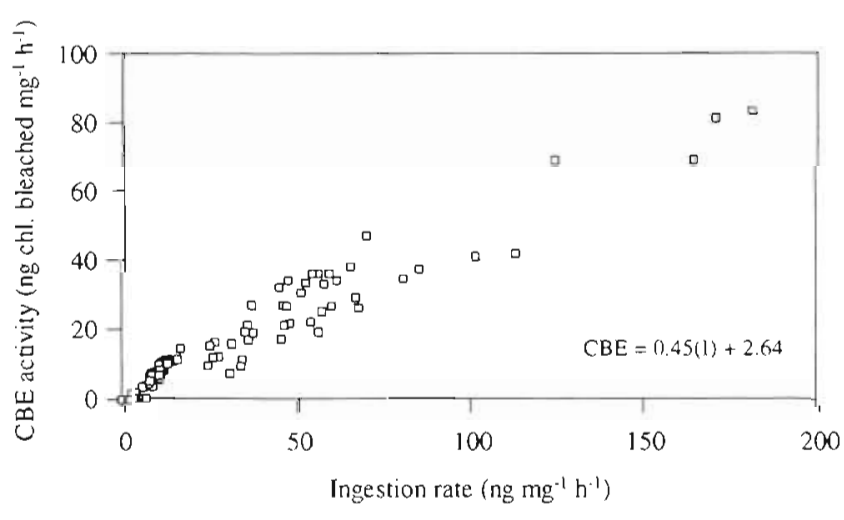

Fig. 7 Relationship between the estimated 'chlorophyll bleaching enzyme' (CBE) activity and initial ingestion rate for Type A Expts 
(1982) found that cell free extracts of diatoms degrade chl a to colourless products in vitro, in the dark, and that for Skeletonema costatum, at $20^{\circ} \mathrm{C}$, the degree of chl a destruction tended to a limit of ca $45 \%$. Intact cells did not degrade chl $a$, so that $C B E$ activity was normally latent, perhaps because it is stored in membrane-bound vesicles. Copepods, by grinding up the diatoms during ingestion, mix the algal enzymes with their substrates, thus causing chl a destruction.

Another reason for suggesting that much of the CBE activity is derived from the algae is the fact that its activity (as manifested by the degree of chlorophyll destructionj does not behave like the activities of other digestive enzymes (as manifested by the assimilation efficiencies for $\mathrm{POC}$ and $\mathrm{PON}$ ). High assimilation efficiencies for POC and PON occurred at high ingestion rates, whereas degrees of chlorophyll destruction were high only at low ingestion rates (Table 4). In addition, chlorophyll degradalion apparently occurs very rapidly as food enters the gut, whereas the high assimilation efficiencies for carbon and nitrogen probably result from prolonged digestion of carbohydrate and protein and assimilation of end-products all along the gut.

While the correlation between CBE activity and ingestion rate is strong, it does not exclude the possibility that algal or copepod CBE activity may vary with species composition or physiological state. For individual experiments, for example, correlations between $C B E$ activity and initial ingestion rate were always high, but the values for the slopes (algal CBE) varied between 0.29 and 0.51 , and the values for the intercepts (copepod CBE), between 1.20 and $4.64 \mathrm{ng}$ $\mathrm{mg}^{-1} \mathrm{~h}^{-1}$. Differences in the slopes might have resulted from differences in algal composition, because algal species exhibit variable levels of chlorophyll degrading ability in vitro, with some diatoms (e.g. Skeletonema costatum) showing high levels of $\mathrm{CBE}$, and others (e.g. Thalassiosira pseudonana) relatively low levels (Owens \& Falkowski 1982). Algae with low inherent $\mathrm{CBE}$ activity will give low slope values, and low degrees of chl a destruction at high ingestion rates. Differences in values of the $y$-intercept between experiments might have been due to physiological differences between copepod populations. It is also possible, however, that the differences seen in both parameters might merely be reflecting the oversimplicity of the analysis. The incubations were for $12 \mathrm{~h}$, and the degrees of chlorophyll destruction were measured over that time. Ingestion rates, on the other hand, were represented by instantaneous values, i.e. initial ingestion rates, and CBE activities were also given single values. The values of the parameters describing the linear regressions would have depended on experimental conditions because, con- trary to the assumptions of our simple model, both CBE activity and ingestion rate would have been changing during the course of an incubation. Thus, although this analysis has provided a mechanistic interpretation of how chl a destruction occurs, which should be generally applicable, the values of the parameters may not be particularly significant.

Our interpretation predicts the high level of variability in perceived degrees of chlorophyll destruction at low intitial ingestion rates (Fig. 4). In these incubations degrees of chlorophyll destruction would have been increasing with time as ingestion rates decreased, but at different rates in each incubation, because densities of copepods and their filtration rates were different. Additional variability might also occur if variable incubation times were to be used. One might suppose that short incubation times (ca 1 to $3 \mathrm{~h}$ ) would be preferable so that food concentrations would change only minimally, but, in our experience, they are not recommended. Copepods do not always start feeding immediately when they are introduced into a carboy of food, and even the action of mixing the carboy can apparently cause a temporary decrease in grazing activity (Head 1988). Furthermore, as discussed above, estimates of pigment degradation obtained using a Turner fluorometer may be more susceptible to error if short incubation periods are used.

In summary, this study has shown that chl a destruction by copepods grazing on phytoplankton occurs rapidly at an early stage of feeding and that phaeopigments are not intermediates in the process. The degree of destruction varied with ingestion rate, and the relationship between the 2 could be explained by invoking the presence of 2 pools of enzymes capable of rendering chl a into colourless residues (so-called CBE): one derived from the copepods themselves, and one from the ingested algae. In this study, previous feeding history had less of an effect on the level of CBE activity in copepods than it did on filtration rate, which in turn affected both ingestion rate and the degree of chlorophyll destruction. This interpretation can explain, and indeed predicts, the high degree of variability in perceived degrees of chl a destruction such as was observed here and has been seen elsewhere. These findings also suggest that measurements of gut pigment concentrations will reflect the degree of chl a destruction which is occurring, because destruction occurs very early during ingestion. On the basis of our findings we would caution that measurements of ingestion rates derived using the gut fluorescence method which ignore chlorophyll destruction are fundamentally flawed, although our greater understanding of the process may lead us to some predictive capacity in this area in the future. 
Acknowledgements. The authors thank Jeff Anning for technical assistance during the cruise in 1992, and the officers and crew of the CSS 'Hudson' (1994) and CSS 'Parizeau' (1992) for their help. Financial support was provided by Task 4.8 of the Canadian Program of Energy Research and Development (PERD) and the Ocean Climate component of the Canadian Green Plan

\section{LITERATURE CITED}

Baars MA, Oosterhuis SS (1984) Diurnal feeding rhythms in North Sea copepods measured by gut fluorescence, digestive enzyme acitivty and grazing on labelled food. Neth J Sea Res 18:97-119

Brown SB, Houghton JD, Hendry GAF (1991) Chlorophyl\} breakdown. In: Scheer H (ed) Chlorophylls. CRC Press, London, p 465-489

Conover RJ, Durvasula R, Roy S, Wang R (1986) Probable loss of chlorophyll-derived pigments during passage through the gut of zooplankton, and some of the consequences. Limnol Oceanogr 31:432-435

Daley RJ (1973) Experimental characterization of lacustrine chlorophyll diagenesis. II. Bacterial, viral and herbivore grazing effects. Arch Hydrobiol 72:409-439

Dam HG, Peterson WT (1991) In situ feeding behavior of the copepod Temora longicornis: effects of seasonal changes in chlorophyll size fractions and female size. Mar Ecol Prog Ser 71:113-123

Hassett RP, Landry MR (1988) Short-term changes in feeding and digestion by the copepod Calanus pacificus. Mar Biol 99:63-74

Head EJH (1988) Copepod feeding behavior and the measurement of grazing rates in vivo and in vitro. Hydrobiologia 167/168:31-41

Head EJH (1992) Gut pigment accumulation and destruction by arctic copepeods in vitro and in situ. Mar Biol 112:583-592

Head. EJH, Harris LR (1987) Copepod feeding patterns before and during a spring bloom in Bedford Basin, Nova Scotia. Mar Ecol Prog Ser 40:221-230

Head EJH, Harris LR (1992) Chlorophyll and carotenoid transformation and destruction by Calanus spp. grazing on diatoms. Mar Ecol Prog Ser 86:229-238

This article was submitted to the editor
Head EJH, Harris LR (1994) Fceding selectivity by copepods grazing on natural mixtures of phytoplankton determined by HPLC analysis of pigments. Mar Ecol Prog Ser 110: $75-83$

Jeffrey SW, Wright SW (1994) Photosynthetic pigments in the Haptophyta. In: Green JC, Leadbeater BSC (eds) The haptophyte algae. Clarendon Press, Oxford, p $111-132$

Lopez MDG, Huntley ME, Sykes PF (1988) Prgment destruction by Calanus pacificus: impact on the estimation of water column fluxes. J Plankton Res 4:715-734

Morales CE, Harris RP, Head RN, Tranter PRG (1993) Copepod grazing in the oceanic northeast Atlantic during a 6 week drifting station: the contribution of size classes and vertical migrants. J Plankton Res 15:185-211

Owens TG, Falkowski PG (1982) Enzymatic degradation of chlorophyll a by marine phytoplankton in vitro. Phytochem 21:979-984

Pasternak AF, Drits AV (1988) Possible degradation of chlorophyll-derived pigments during gut passage of herbivorous copepods. Mar Ecol Prog Ser 49:187-190

Penry DL, Frost BW (1991) Chlorophyll a degradation by Calanus pacificus: dependence on ingestion rate and digestive acclimation to food resources. Limnol Oceanogr 36:147-159

Roy S, Harris RP, Poulet SA (1989) Inefficient feeding by Calanus helgolandicus and Temora longicornis on Coscinodiscus wailesii: quantitative estimation using chlorophyll-type pigments and the effects on dissolved amino acids. Mar Ecol Prog Ser 52:145-153

Roy S, Poulet SA (1990) Laboratory study of the chemical composition of aging copepod fecal material. J Exp Mar Biol Ecol 135:3-18

Runge JA (1980) Effects of hunger and season on the feeding behavior of Calanus pacificus. Limnol Oceanogr 25: $134-145$

Saiz E, Alcaraz M (1990) Pigment gut contents of copepods and deep phytoplankton maximum in the Western Mediterranean. J Plankton Res 12:665-672

Spooner N, Keely BJ, Maxwell JR (1994) Brologically mediated defunctionlization of chlorophyll in the aquatic environment. I. Senescence/decay of the diatom Phaeodactylum tricornutum. Org Geochem 21:509-516

Manuscript first received: June 13,1995

Revised version accepted: November 2, 1995 